\title{
CANADIAN DISPUTE RESOLUTION CORPORATION
}

\section{DAVID G. GOULD, Q.C.}

Canadian Dispute Resolution Corporation ("CDRC") is Canada's largest independent mediation service organization. CDRC serves clients whose priority is to negotiate early settlement of their disputes, thus saving time, expense and human resources. We have offices in Halifax, Toronto, Winnipeg, Regina, Calgary, Edmonton and Vancouver and we maintain a roster of highly skilled mediators, all with many years of legal or business experience in each location.

Major Canadian insurance companies, law firms, construction companies, labour organizations, professional associations plus private and public sector businesses are among CDRC's clients. Our success in assisting parties to settle cases can be directly attributed to our pre-mediation facilitation. We interest parties in negotiating with each other, establish terms for negotiating that allow for each party's interests, ensure that the parties with knowledge and full authority attend the mediation, ensure that there is adequate time for full and frank discussion and provide mediators conversant in the area of the dispute and skilled in mediation techniques.

\section{WHY MEDIATION?}

At its core, our litigation system is adversarial in nature, utilizing a structured set of rules aimed ultimately at establishing the "truth." In litigation, each side commits resources, time and money preparing to prove its case and to defeat the opposition. Yet neither litigation nor custom sets a time for the parties to negotiate. In today's complex world, many disputes are far more likely to require a solution rather than a decision. The parties themselves have the best understanding of their own underlying interests and needs. In litigation, often the client's true interests become lost in the tactics of case building.

It is important to understand that mediation is both an event and a process.

The success rate in commercial mediation approaches 80 percent at or shortly after the mediation conference. The two most important factors, having an impact on the success rate, are:

1. The skills and abilities of the mediator in effectively managing the negotiation process; and

2. The willingness of the parties to participate in a fully non-adversarial problemsolving exercise.

The second factor is positively impacted by the amount and the effectiveness of premediation preparation of the parties, usually referred to as "mediation facilitation." 
Mediation, as a process, is a formalized intention to negotiate a solution. When parties agree to mediation, they establish a common and powerful purpose to resolve the matter in dispute by agreement on or before a specific date. The focus shifts from adversarial preparation to that of persuasion and information exchange.

Given that counsel's primary obligation is to protect their respective client's interests, counsel will want to prepare the case and the client so as to be able to negotiate the best solution. It is helpful to have a professional facilitate getting to the mediation itself. CDRC's job includes:

- obtaining the agreement of the parties to participate in mediation;

- encouraging exchange of information and, where appropriate, settlement proposals prior to the mediation;

- encouraging full and frank discussions and establishing ground rules for mutual respect in the negotiations;

- $\quad$ handling authority issues;

- obtaining Summary Reports and prepare the mediator;

- handling logistics - date, time, duration, location;

- providing accurate cost estimates and assisting the parties to negotiate premediation cost sharing agreements.

The parties may not be at the same place in their understanding of and preparation for mediation. Statistically, more than 40 percent of all the cases referred to CDRC settle prior to the mediation conference, largely as a result of the parties' facilitated focus on settlement.

In a mediation conference, the mediator chairs the meeting, maintains respect, and clears the way for the parties to negotiate effectively. The mediator assists the parties to focus on interests and not positions and be effectively non-adversarial - tough on the problem, but gentle with the people.

The benefits of mediation as an event are many:

- Parties tend to buy into a solution they have had a hand in creating themselves;

- Early negotiated settlements save resources - time, energy and money;

- A win-win solution or even an acceptable compromise preserves future relationships;

- Clients with an effective solution in hand appreciate the professional advisor who orchestrated that solution and want to work with him or her again;

- The courts are freed up to deal with cases that really need to be there.

\section{WHEN TO MEDIATE?}

Our suggested rule of thumb is that you assume mediation is appropriate and then look for compelling considerations in tactics, preparation, or complexity of legal issues 
that mitigate against the mediation option. Consider applying for mediation of any dispute when:

- the trial date is within six months and the file is just waiting for trial;

- negotiations have broken down and the parties are locked into litigation steps (the greater the disparity between the respective parties' positions, the greater the need for mediation);

- you have made an unanswered offer and the other side is showing a reluctance to negotiate with you;

- litigation is about to begin or has just begun (one last try before filing Statement of Claim or Statement of Defence or booking discoveries);

- the litigation involves multiple parties and traditional (grapevine) negotiations are not working;

- there are many complex issues that can be narrowed to one or two major issues;

- $\quad$ "people" issues have been getting in the way of effective negotiations of the substantive problem.

It is our hope this article has provided you with information that will assist you in assessing whether or not the mediation option will be suitable for your cases. Additional information can be obtained by contacting the CDRC office nearest you. 